\title{
Female Migration, Cultural Context, and Son Preference in Rural China
}

\author{
Yao Lu and Ren Tao \\ (Final version to appear in Population Research and Policy Review)
}

\author{
Contact information \\ Yao Lu \\ Department of Sociology, Columbia University \\ 501 Knox Hall \\ New York, NY 10027, USA \\ Phone: 212-854-5442 \\ Email:yao.1u@columbia.edu
}

\begin{abstract}
How does female out-migration reconfigure gender values surrounding son preference in origin communities? We propose that the feminization of migration has the potential to infuse origin communities with economic and ideational changes that may challenge son preference. Rural China provides an interesting setting, both because its unprecedented labor out-migration has increasingly included women and because of its persistent son preference. Using data from rural China and instrumental variable regressions to adjust for potential endogeneity bias, this study shows that out-migration of women, but not of men, attenuates son preference among those in origin communities. The role of female out-migration transcends families with direct ties to migration and extends to the entire village. However, cultural context and family positions within that context condition the role of female migration: specifically, the preferences of individuals in families and villages embedded in strong patrilineal cultural practices are less likely to be shaped by female out-migration.
\end{abstract}




\section{Introduction}

Over the past several decades, the magnitude of women who migrate has grown tremendously around the globe (IOM 2010). This trend has generated considerable interest in examining the important ways in which migration reshapes gender relations and gender roles in destination societies (Pedraza 1991; Curran et al. 2006; Donato et al. 2006; Pessar and Mahler 2003). Few studies, however, have investigated the potential of migration for value transformation (Portes 2010). Even fewer have assessed this question by disaggregating gendered migration patterns or by studying migrant-sending areas. To fill this gap, the present study examines how gendered migration reconfigures traditional values underpinning son preference among people in origin areas.

China provides an interesting case for study. Massive rural-to-urban migration has brought about profound socioeconomic transformation over the past three decades (Murphy 2002). This transformation is in large part an outgrowth of women's increasing participation in migration (Zhang 2007). In popular discourse, Chinese migrant women are increasingly portrayed as potential agents of social change (Jacka 2005). Despite these areas of development, one persistent feature of rural China is a preference for sons over daughters, which is deeply rooted in patrilineal cultural practices (Murphy et al. 2011).

How does female migration shape son preference in rural China? We propose that female migration brings about economic and ideational changes to families and communities in migrantsending areas that can attenuate son preference. Migration enables women to acquire new economic roles and accrue economic power (Pessar and Mahler 2003), subsequently redefining 
the perceived economic and social values of women. The experience of migration also leads to the adoption and diffusion of more gender-egalitarian values (Hondagneu-Sotelo 1994). The process of transmission and diffusion implies that female migration can have an aggregate effect on cultural values that extends beyond the immediate family context to the wider social environment (Levitt and Lamba-Nieves 2011).

The role of female migration, however, may not be uniform. Rather, it is likely to be intertwined with the immediate and broader cultural context within which individuals rework

their values. In rural China, long-standing patrilineal cultural practices such as ancestral worship serve to reinforce traditional gender norms. The informal constraints imposed by these traditions can impede the potential for female migration to shape son preference.

The data are from a national survey conducted in 2008 in rural China. In the analysis, we examine whether the consequences of out-migration for villager's son preference differ by the gender of migrants. We also distinguish between gendered migration patterns at the household and the village level to evaluate the externality of the migration effect. We further assess differences in the role of female migration across familial and community cultural contexts. An instrumental variable approach is adopted to reduce potential endogeneity bias.

\section{Migration and Gender Dynamics}

Around the world, women no longer migrate as dependents of husbands or male relatives. They increasingly migrate in their own capacity as workers (IOM 2010). These trends have resulted in a closer attention to a gender perspective in migration research (Pedraza 1991; Curran et al. 
2006; Donato et al. 2006; Pessar and Mahler 2003). Previous scholarship has largely examined how gender shapes the migration and adaptation process, and how migration reconfigures gender relations within the household, especially in destination societies (Grasmuck and Pessar 1991; Hondagneu-Sotelo 1994; Kanaiaupuni 2000; Curran and Rivero-Fuentes 2003). Little research has investigated the way in which gendered migration transforms traditional values for those in origin areas.

Previous migration and gender research points to several processes associated with female migration that could shape cultural values in origin communities. First, for many women, migration opens up previously unavailable income-generation opportunities and status mobility routes (Pessar and Mahler 2003). This increases women's autonomy and self-esteem, in turn providing women with greater leverage in making egalitarian claims within their own homes and broadens their social entitlements (Grasmuck and Pessar 1991; Hondagneu-Sotelo 1994). Nevertheless, it is cautioned that the shift of gender roles after migration may be uneven, depending on the patterns of migration such as whether migration occurs as a family, individually, or stepwise (Hondagneu-Sotelo 1994).

From the perspective of sending communities, as women become economically independent after migration, they are often better able to make significant economic contributions to origin families (Fan 2008). In many settings, women are even found to be more likely to remit earnings than men (Curran et al. 2006). Migration also leads to the adoption of neo-local (versus patrilocal) living arrangements (Zhang 2007). This further allows migrant women to contribute more freely to their natal families, gradually shifting the obligation to 
support elderly parents away from sons toward both sons and daughters. When female outmigration evolves into an essential part of the family and village economy, women's position tends to increase, followed by more egalitarian gender values (Zheng et al. 2001).

Second, migration often drives ideational change and the transmission of new values related to gender. Whether from rural to urban areas or across national boundaries, migrants are constantly exposed to more "modern" gender norms that contrast sharply with the often more traditional gender system pervading their origin communities (Hondagneu-Sotelo 1994; Foner 2002). This change could be transformative for migrants, especially migrant women, leading to a development of gender consciousness (Chafetz 1999). Such ideational shift could improve women's position over and above the impact migration has on economic autonomy.

Migrant women's more egalitarian gender attitudes may infuse origin families and communities through social transmission (Curran et al. 2006). This process is theorized in the concept of social remittances - the new attitudes and practices that migrants adopt in destinations and transfer back to their family and friends in origins through myriad forms of interactions such as visits, return, letters, phone calls, and e-mails (Levitt 1998). Such transmission within longstanding affective ties is usually more effective than attitudes produced by mass media or more formal channels (Lindstrom and Munoz-Franco 2005). The value transmission may also be reinforced by economic remittances, especially when recipients' livelihoods heavily depend on remittances (Levitt 1998).

The adoption of new values by families of migrants may influence the subsequent 
adoption of similar values by the rest of the community (Levitt and Lamba-Nieves 2011). In this way, migration exerts an aggregate effect on value change that extends beyond the immediate family context. This community-wide diffusion is realized through social learning, especially in the form of interpersonal interactions (Montgomery and Casterline 1996). The spillovers may also be facilitated by social learning through observation (or the "demonstration effect") (Montgomery and Casterline 1996). Even when families and friends of migrants do not deliberately circulate information, the new social and economic roles assumed by migrant women offer concrete examples of the contributions women can bring to families and communities. Although some migrant women may be constrained by the wider social and gender structure in their destinations, in whole their status is substantially improved after migration, particularly as perceived by those remaining in the origin (Zhang 2007). The process of social influence may also be at work. In this context, shared group values play a key role by placing pressure on individuals to conform to group norms (Montgomery and Casterline 1996). Therefore, the transformation of individual cultural values naturally requires changes in the local normative context, as fostered by community-wide ideational diffusion.

\section{Context Dependence}

The pattern of value change is often path dependent (Inglehart 1989). Whereas socioeconomic development results in general shifts toward more egalitarian gender roles, cultural legacies continue to exert a strong influence on gender values and the extent to which new values are adopted.

Echoing this view, a strand of research on migration and gender dynamics has questioned 
the positive impact of migration on gender equality. These studies emphasize the interaction between the structural and familial contexts in conditioning gender relations. Depending on the gender stratification system in the larger context of reception and migrants' structural position within such a context, migration may either redress or reinforce patriarchal gender asymmetries (Kibria 1990; Hondagneu-Sotelo 1994; Parrado and Flippen 2005). In the settings characterized by strong patriarchal norms or marginalization of migrants, female migrants may become more rather than less dependent on their partners and therefore less able to wield power within and outside their families (Kibria 1990; Parrado and Flippen 2005).

\section{Son Preference, Patrilineal System, and Migration in China}

China, rural China in particular, is among the societies with most persistent son preference (Gupta et al. 2003). ${ }^{1}$ Parents in rural China are often reluctant to complete their childbearing without having at least one son. This has resulted in a distorted sex ratio at birth, which has exceeded the biologically normal range (106 male births per 100 female births) since the late 1980s (116.9 in 2000, 118.6 in 2005, and 118.1 in 2010; National Bureau of Statistics 2010) (Banister 2004; National Bureau of Statistics 2011). China's rigid birth control policy, which restricts couples to only one child in cities and two children in the countryside (when the first child is a girl), is widely believed to have exacerbated the distorted sex ratios by pushing parents to bear a son within the confines of a small family size (through sex-selective abortions) (Zeng et al. 1993; Hesketh et al. 2005). Son preference also results in discriminatory treatment favoring sons over daughters, leading to substantial gender differentials in health and education (Graham et al. 1998; Song and Burgard 2008). 
The strong son preference exists in part for pragmatic reasons. Agricultural and manual labor put a premium on sons (Gupta et al. 2003). Having a son also secures a viable source of support in old age. Parents' heavy financial dependence on sons is reinforced by weak institutional support for the elderly in rural China (e.g., the lack of a pension system) (Ebenstein and Leung 2010). It is also a result of the patrilocal custom under which daughters join the husband's family upon marriage, essentially making daughters an economic liability to their natal homes (Parish and Whyte 1978). ${ }^{2}$

Standard explanations for son preference also focus on cultural factors associated with patrilineal family systems (Gupta et al. 2003). The core norm in China's patrilineal culture is to perpetuate the lineage bloodline, which only male descendants can fulfill (Cohen 2005). The system is held together through patrilineal cultural practices like ancestor worship ceremonies, the repair of ancestral shrines, and the compilation of genealogies, all of which affirm shared patrilineal descent (Cohen 2005). Such practices reinforce the influence of traditional gender norms by reminding performers of filial obligations to carry on the family line. Empirical studies find that individuals in families that engage in these practices hold stronger son preference ( $\mathrm{Li}$ and Lavely 2003; Murphy et al. 2011).

In juxtaposition with the persistent son preference is large-scale internal migration, mostly from rural to urban areas. Now estimated at over 220 million people (NBS 2011b), this migratory stream has been conditioned by a pre-existing bifurcated social structure (the hukou registration system) that separates urban and rural Chinese into two categories of citizens (Solinger 1999). As a result, permanent settlement is difficult and many migrants are circular and 
maintain close contacts with families back home. Given this strong connection, the livelihoods of people in rural origins are altered by increased levels of out-migration. Out-migration is linked to income diversification and poverty alleviation in rural China (Du et al. 2005). Yet, little research has examined the non-economic impacts of out-migration on rural China.

An increasing number of women, married or single, have joined the migration flows (Fan 2008). Some suggest that China's economic explosion is in large part an outgrowth of women's economic empowerment (Zhang 2007). By 2000, women made up more than a third of the migrant population; by 2010, the percentage had increased to 45\% (NBS 2011). The reasons for female migration have shifted away from marriage-related to work-related purposes (Fan and Huang 1998; Liang and Ma 2004; Jacka 2005). Chinese migrant women tend to be young. More than twice as many migrant women are between the ages of 15 and 29 than those older than age 30 (Liang and Ma 2004). Although many women migrate before marriage and then return home to marry, they often migrate again either with or without their husbands (Roberts et al. 2004). Inspired by the younger cohort of migrant women, an increasing number of married women have begun to migrate for work (Roberts et al. 2004).

\section{How Does Female Out-migration Shape Son Preference in Rural China?}

As discussed above, we contend that female migration is associated with material and ideational change that could elevate the social value of women. This change could further raise the perceived values of daughters and prompt individual and families in migrant-sending areas to critically re-evaluate and rework traditional values of son preference. At an aggregate level, female migration is likely to infuse village with value change that transcends people directly 
connected to female migrants. Within the village, people may in daily conversation acknowledge the amount of remittances sent and the new roles adopted by migrant daughters (Murphy 2002). As female migration evolves into an essential part of village life, this kind of information is reiterated and filters throughout the community.

We hypothesize that female out-migration attenuates son preference among people in rural origin communities: specifically, individuals in villages with a higher level of female migration tend to have lower son preference than individuals in villages with a lower level of female migration (Hypothesis 1). By contrast, male out-migration may not mitigate son preference and may even exacerbate it. For one thing, male migration and remittances fulfill normative expectations: successful migration and inflows of remittances improve household standards of living, making origin families heavily dependent on the economic contribution from sons (Ming and Zhang 2011). This process could reinforce the value of male offspring to parents. For another, male and female migrants may differ in their gender egalitarian values - with women more supportive of gender-equal views and men more supportive of traditional gender attitudes (Inglehart and Norris 2003). Thus, the adoption and diffusion of egalitarian gender values tend to be stronger when women migrate than when men migrate.

Cultural contexts may shape the role of female out-migration for son preference. We focus on the normative constraints imposed by patrilineal cultural practices. In rural China, patrilineal rituals, such as ancestor worship, consolidate traditional gender norms by reminding the performers of their filial obligations to carry on the family line with male descendants, and by necessitating participation in wider social interactions centered on patrilineal descent (Santos 
2006). Individuals and families embedded within such practices and structures thus tend to adhere to traditional gender views.

We hypothesize that such cultural contexts inhibit the role of female out-migration: the role of female migration in attenuating individual son preference is weaker for people in families and villages engaged in patrilineal rituals, than for those in families and villages facing less patrilineal pressure (Hypothesis 2).

\section{Data, Variables, and Methods}

\section{Data}

The data are from the 2008 Rural Survey of Land, Migration and Local Governance. The survey used a multistage stratified sampling strategy to select counties, townships, and villages in six provinces in each of China's six commonly recognized geographical regions. The selection of households and respondents were based on random sampling. The final sample includes 2196 people from 117 villages. The sampling strategy is discussed in detail in ("Appendix 1: Sampling Strategy" section).

\section{Variables and Methods}

The dependent variable is son preference. The survey measures the intensity of respondents' son preference by asking them to rate on a scale of one to five the extent to which they agree or disagree with the statement (from strongly disagree to strongly agree): "I think that it is necessary to have at least one son." This variable is coded in a way that higher values indicate 
stronger son preference. Given the sensitivity of questions about fertility preferences in China's political context, we felt that this relatively neutral phrasing would be more likely to elicit truthful responses than questions asking about an individual's fertility intentions. Because we study individuals at different stages of the life cycle, questions about actual intentions would not be relevant in some cases.

The main predictors are gender composition of out-migration measured at both the household and village levels. Household measures were created using information on migration in the household roster for each household member, where members include household head, his or her spouse and children (living in or out of the household), and any other people registered in the household. For each person, information is available on the year that a household member first migrated out of the county for work, and whether a household member was out of the county for work during the year prior to the survey. ${ }^{3}$ Based on these two questions, we constructed two sets of out-migration measures. One is a cumulative household out-migration measure, defined as the proportion of household members age 16 and above with any previous out-migration experience. The other is a current migration measure, defined as the proportion of household members age 16 and above who migrated for work during the past year. We separate the cumulative and current out-migration measures to study both the longer-term and more immediate effects of female out-migration. In addition to these composite measures, we separated the out-migration measures by gender and constructed cumulative and current measures of female and male out-migration ratio. They are defined, respectively, as the proportion of female and male household members with any or current migration experience. Finally, we created variables indicating the level of female out-migration relative to that of male 
out-migration by differencing the household cumulative (or current) female and male outmigration measures.

Following the same procedure, we constructed female and male out-migration ratio measures at the village level, aggregating members of all sampled households within each village. For example, the village cumulative female out-migration ratio is defined as the proportion of female villagers age 16 and above who ever migrated for work. We also created difference measures in female and male out-migration ratio at the village level. These aggregated village measures reflect real village out-migration levels relatively well because the sampled households were randomly selected. To evaluate the validity of these aggregated measures, we compared them (after restricting to the same age range) with reports from the village office on the proportion of males and females age 18-35 that went out for work during the past year (the only measure directly available). The comparison shows similar levels of out-migration using the two measures. We thus focus on the aggregated measures because they do not pose age restrictions and allow for examining cumulative out-migration patterns.

Other covariates include basic individual characteristics such as age, sex, educational attainment, and marital status, whether the respondent has a son, religion, and whether the respondent ever migrated himself or herself (return migrant). Younger respondents and those with higher levels of education may have weaker son preference because they are more receptive to new ideas including more equal gender norms (Murphy et al. 2011). While being female may be associated with weaker son preference, women in patrilineal societies may want a son as much as men do because a son secures a woman's position within the family (Stacey 1983). 
Married people may be more likely to express stronger son preference due to the influence of patrilineal marriage norms. Whether the respondent has any male children may also be closely associated with son preference because people may not be willing to express a value inconsistent with reality ( $\mathrm{Li}$ and Lavely 2003). Religion is measured by respondent's religious affiliation. We distinguish between eastern religions (Taoism, Buddhism, and Chinese folk religions) and western religions (Christian including Protestant and Catholic). Eastern religions may be particularly likely to be associated with more traditional gender norms (Peek et al. 1991). We also control for an individual's own migration experience because it may be associated with more gender egalitarian attitudes.

At the household level, we control for household per capita annual income, which was calculated by adding household income from all sources divided by the number of resident members in the household. It may be negatively associated with son preference because highincome families may not have a great need for a son to provide old-age support. But well-to-do families may have stronger desires for sons because sons are expected to inherit family property (Miller 1981). We also control for family generational composition. Because older generations may have important influence over the preferences of younger adults, and because maintaining a multigenerational family may itself indicate adherence to patrilineal arrangements ideals (Attané 2009), son preference may be stronger in families where adults co-reside with their parents or parents-in-law. We further adjust for the size of families' arable landholdings, which may be associated with stronger son preference because more land requires more labor (Li and Lavely 2003). 
Village-level controls include village income per capita and the proportion of villagers with high school education or above. Information on these two measures is directly available from the village records. We expect the level of son preference to be weaker in villages with a high level of local socioeconomic and human development.

One important set of variables is patrilineal sociocultural practices at the household and village level. We measure patrilineal practice by ancestor worship — whether the household annually worships ancestors in the patrilineage, and whether the village holds collective ancestor worship ceremonies at least every few years. We expect the presence and participation in such patrilineal rituals to reinforce son preference.

Because son preference is measured on a five-point scale and because of potential endogeneity bias, we use ordered probit regressions with instrumental variables. Some unobserved factors might be related to both the likelihood of female out-migration and son preference. For example, households and villages embracing more equal gender views may be more likely to send women out for work and also to have weaker son preference. Conversely, female migration could be adopted as a strategy to achieve certain goals, such as having a son or providing for a son's education. The two scenarios would lead to an overestimation and underestimation, respectively, of the effect of female migration on son preference.

To address this issue, we use natural shock as an instrument. The survey asks whether the village experienced natural climatological disasters that severely influenced agricultural production (which include flooding, drought, freeze, and pest infestation) in 2007 . About $30 \%$ of 
the villages were hit by at least one type of natural hazard. This measure also provides considerable variability across villages. The occurrence of natural disasters is likely to give an exogenous shock to the migration outflow. Previous work shows that the occurrence of climatological disasters in a small tract such as a village can be seen as random, though natural hazards in a larger region or geological disasters (e.g., earthquakes) may occur repeatedly and not be random in the long run (Wang 2007). In the face of exogenous shocks that increase farmincome variability, off-farm work through migration tends to be adopted as an important (temporary or long-term) risk aversion strategy (Mishra and Goodwin 1997; Halliday 2006).

Natural shocks are likely to increase female out-migration at a greater rate than male outmigration. In the wake of a natural shock and agricultural output decline, the motivation for women to migrate may be especially pronounced. This is because male migration is generally more prevalent than female migration and may be close to saturation among the prime-age group. Women are thus more likely to be available to substitute farm and care work with offfarm income to cope with household economic crises. Another perspective suggests that hazardous conditions tend to put women at greater risk than men, because women's access to resources is often inferior to that of men (Enarson and Morrow 1998). Given their vulnerability, women may have a greater incentive to migrate after a disaster.

We use a dichotomous measure of whether the village experienced any climatological shock in 2007 as an instrumental variable for the gender difference in out-migration at the village level. The model was estimated as a simultaneous bivariate model, where the first equation is an ordered probit regression: 


$$
y_{i}^{*}=\alpha M_{i}+\beta X_{i}+\varepsilon_{i}
$$

where $y_{i}{ }_{i}$ is the latent dependent variable for individual $i, M_{i}$ stands for key explanatory variables (out-migration ratios at both household and village level), $X_{1}$ is a vector of control variables, and $\varepsilon_{i}$ are the error terms distributed as probit (cumulative density of standard normal distribution). We can only observe the categories of response, and we use observed (censored) $y_{i}$ in the estimation:

$$
\begin{aligned}
& y_{i}=0, \text { if } y_{i}^{*} \leq \mu_{0} \\
& y_{i}=j, \text { if } \mu_{c-1} \leq y_{i}^{*} \leq \mu_{c}, c=1,2,3,4,5
\end{aligned}
$$

Eq. 1 is estimated simultaneously with a linear regression (equation 2) for the village outmigration ratios variable $\left(M_{j}\right)$, using a limited information maximum likelihood (LIML) estimator.

$$
M_{j}=\gamma Z_{j}+\lambda X_{j}+v_{j}
$$

where $Z_{j}$ is the instrumental variable and $X_{j}$ represents the set of village-level covariates as in Eq. 1. This model assumes that the disturbances $\left(\varepsilon_{i}\right.$ and $\left.v_{j}\right)$ have a bivariate normal distribution (Roodman 2008). We further adjusted this ordered probit IV regression for clustering of observations at the village level.

To better account for the hierarchical structure of the data, we also estimated a corresponding set of multilevel ordered logistic regressions (Rabe-Hesketh and Skrondal 2012). The model is formulated as below:

$$
y_{i j}^{*}=\alpha M_{i j}+\beta X_{i j}+u_{j}+\varepsilon_{i j}
$$


where $y_{i j}^{*}$ is the latent dependent variable for individual $i$ in village $j, u_{j}$ is a set of random effects, and other notations are similar to those in Eq. 1. We did not estimate a multilevel ordered regression with an instrumental variable because statistical algorithms for incorporating a multilevel framework in an ordered IV regression have not been fully developed. Taken together, these two sets of regressions provide more robust results than results based on any one set.

\section{Descriptive Statistics}

Table 1 presents descriptive statistics of out-migration ratio measures. Cumulative out-migration measures show greater prevalence than the current out-migration measures, but the patterns of these two measures are similar. On average, the proportion of people who have ever migrated in the household is over $25 \%$. The proportion is close to $26 \%$ at the village level. There is a substantial difference between male and female out-migration, with women being less likely to migrate than men. For example, slightly more than $15 \%$ of female family members have migrated before, compared to over $33 \%$ of men. At the village-level, the proportions are $17 \%$ and $34 \%$, respectively, for women and men. The gender difference in the out-migration ratio is negative, although there is considerable variation in the household and village gender composition of out-migrants.

[Table 1 about here]

Table 2 presents descriptive statistics of other variables. The average value for son preference is 3.8 (on a scale of 5). Because a higher value indicates greater son preference (and 4 indicates agreement with the statement about son preference), this suggests that rural people 
generally hold quite strong preferences for male children. We also note some key characteristics of the respondents. About $18 \%$ of respondents have had some migration experience themselves. Roughly $60 \%$ of the sample is male, slightly above the national rural average of 56 percent. The age and educational composition of the sample is affected by the disproportionate involvement of younger and better-educated rural people in migration. The average age is about 49 years, while the average education is only 6 years. In part reflecting the older age of the sample, $96 \%$ of respondents are married. Over $44 \%$ of the respondents indicate that they are religious, among whom a majority are believers of eastern religions. At the village level, only a small proportion of the villagers have received education at or above the high-school level. With respect to patrilineal practices, over $33 \%$ of the households participate in ancestor worship annually. At the village level, $34 \%$ of the villages hold collective ancestor worship.

[Table 2 about here]

We also use supplementary data to study the remittance behavior and son preference of migrants, which provide some evidence for the material and ideological dimensions of transfers from migrants to origin families. Description of data and results are reported in "(Appendix 2: Analyses of Remittance Behavior and Son Preference Using Supplementary Data on Migrants section)".

\section{Regression Results}

Table 3 displays the coefficients from instrumental variable regressions. Results show that an increase in female out-migration (relative to male out-migration) in the village is associated with 
substantially lower son preference. The above results are quite consistent regardless of whether we examine cumulative or current village out-migration measures. The current out-migration measure reflects more immediate influences of migrants' social and economic transfers. Cumulative out-migration, on the other hand, indicates the institutionalization of out-migration in local communities as well as the degree of villagers' connection to the outside world. One noteworthy finding is the more prominent role of village-level out-migration than householdlevel out-migration in attenuating son preference. We also estimated a similar model controlling for only household gendered migration. In this model, the coefficient of the household migration variable is significant. The finding, which this coefficient becomes insignificant once controlling for village-level migration may be taken in part as evidence of the diffusion process. Outmigration leads to broader shifts in traditional values, even among villagers who are not directly connected to out-migration. Overall, village gendered migration emerges as a strong predictor of son preference. These findings provide some support for Hypothesis 1.

[Table 3 about here]

As for other covariates, older people and less educated people tend to hold stronger son preference than younger and more educated people. Another crucial predictor is whether the respondent has any sons (a factor that may reflect not just how people view the importance of having male children, but also the ways people rationalize their views on the matter). Although household income is not significantly associated with son preference-presumably because of the offsetting mechanisms discussed above - the level of economic development in the village shows some importance, with peasants in more economic developed villages showing a lower 
level of son preference. There is a significant association between household and village cultural practices of ancestor worship and son preference. These results suggest that patrilineal cultural rituals are associated with a higher degree of son preference, especially for households that actively participate in such practices.

Unlike the crucial role of continuing migration, return migrants do not report a significantly lower son preference than co-villagers without any migration experience. This finding may partially reflect the diffusion process within families and across the village. It may also be because the economic power and the more gender egalitarian values acquired by migrants tend to weaken after they return home.

In these instrumental variable regressions, the coefficients from the first-stage regression and corresponding $\mathrm{F}$ tests are at or above the threshold of 10 and significant at the 0.001 level. This suggests that the instrumental variable is significantly and positively correlated with village gender difference in out-migration and is therefore not a weak instrument. As we speculated, experiencing a natural shock tends to promote out-migration, especially that of women relative to men. Moreover, the test for the presence of endogeneity, which is based on a test for the statistical significance of the correlation between $\varepsilon_{i}$ and $\nu_{i}$, is insignificant. This suggests that the null hypothesis that village out-migration rate is exogenous cannot be rejected. In other words, unobserved factors do not seem to account for the entire relationship between female outmigration and son preference. In this scenario, ordered logistic regressions are preferred because they yield more efficient estimates. 
For this reason, we also estimated ordered logistic regressions in a multilevel framework. These models not only more adequately adjust for the hierarchical structure of observations, but also allow us to examine separate measures of male and female out-migration. The results are shown in Table 4, which are consistent with the results from the instrumental variable analysis. Models 1 and 3 use current out-migration measures, while the rest use cumulative out-migration measures. Results show that although household out-migration does not seem to be significantly associated with son preference, village out-migration does. Higher female out-migration in the village is associated with lower son preference, while male out-migration leads to stronger bias. For example, consider Model 1, where an increase in village female out-migration ratio by $50 \%$ would decrease the odds of reporting higher versus lower levels of son preference by about $58 \%$ $\left(1-\mathrm{e}^{-1.739 * 0.5}=0.58\right)$. By contrast, an increase in village male out-migration ratio by $50 \%$ would increase the odds of reporting higher versus lower levels of son preference by 1.5 times $\left(\mathrm{e}^{1.849 * 0.5}\right.$ 1=1.52). Results using the difference measure (Models 3 and 4) tell a similar story. Other covariates are omitted but are similar to those presented in Table 3.

[Table 4 about here]

We evaluate the robustness of the results to different model specifications (results not shown), by replacing the out-migration measures with the age-restricted (age 18-35) ratios of male and female migrants in the past year reported by village officials. The average of female and male out-migration ratio is, respectively, 40 and 50\%. They are higher than the measures for the entire age spectrum, highlighting the young age structure of Chinese migrant workers. But these reported measures are relatively similar to measures created by aggregating across the 
sample households (which, for the $18-35$ age group, are $35 \%$ for women and $48 \%$ for men). The role of female out-migration remains prominent.

\section{Contextual Variations in the Role of Female Out-migration}

Our analyses reveal important variations in the role of female migration by household and village cultural context, as measured by patrilineal cultural practices. We included interactions between village migration and cultural context in the regressions. Figure 1 displays the respective role of female migration in different cultural contexts.

For respondents in households that actively perform patrilineal cultural rituals (panel A) and in villages that collectively engage in collective rituals (panel B), the role of female outmigration in attenuating son preference is smaller and less significant (dashed line). In contrast, for respondents in families and villages that are not engaged in such cultural practices (solid line), the coefficient of female migration remains large and significant. This is reflected in the steeper slopes for solid lines. The difference by cultural contexts in panel A is significant at the 0.1 level. The difference in panel B, although lacking statistical significance, shows a similar pattern that among those living in villages embedded in patrilineal cultural practices, the role of female migration for attenuating son preference is rather limited.

[Figure 1 about here]

These results suggest that although son preference tends to vary across villages according to the level of female out-migration, not all individuals in families and villages with similar 
migration levels respond in the same way. Entrenched patrilineal legacies, as reflected in the practices of ancestor worship rituals, tend to reinforce the cultural basis of son preference. This subsequently inhibits the potential shift in an individual's son preference fostered by migration. These results provide some support for Hypothesis 2.

\section{Discussion and Conclusion}

The present study demonstrates how gendered out-migration shapes traditional values surrounding son preference in origin communities in China. We find that female out-migration attenuates son preference while male out-migration exacerbates this bias. The role of outmigration should be situated within the larger context that underpins migration and son preference. First, the potential of female out-migration to spur more modern gender values extends beyond families directly related to migrants to the entire communities at origin. This leads to a stronger role of female out-migration at the village level than at the family level. This finding can be potentially explained by a process of value diffusion within the origin community. It is parallel to the multiplier effect of economic remittances, in which the impact of monetary remittances is often extended to non-migrant households through local development improvements in such areas as consumption, labor supply, and infrastructural growth (Taylor 1999).

Second, the role of female out-migration for shaping individual son preference is intertwined with local context, as reflected in patrilineal cultural practices. Among people in families and villages that engage in such practices, the role of female out-migration in promoting gender-egalitarian values is constrained. By contrast, those in families and villages with less 
patrilineal pressure tend to be more open to migration-induced value change. These results highlight the tenacious nature of cultural legacies in reinforcing traditional values. They also help understand why rural China has continued to be marked by strong son preference in spite of the large and growing outflows of female migrants.

In summary, the present study adopts a gendered approach and takes migration as a driving force for socioeconomic development. It conceptualizes the increasing participation of women in migration as a powerful catalyst of sociocultural change in origin communities. The focus on cultural values and cultural context echoes the call for bringing culture back into the debates about the relationship between migration and development, and for understanding the potential of migration for value transformation (Portes 2010; Levitt and Lamba-Nieves 2012). While earlier work has shown how gender influences migration decisions and outcomes, as well as how migration affects gender relations in the destination, we take a step further to examine how gendered migration reconfigures traditional values related to gender in the origin. Moreover, the findings illustrate that the process of value change induced by migration is not homogeneous. Rather, the immediate and broader cultural context shapes the extent to which the effect of female migration on individual values is realized.

There are important issues beyond the scope of this study. Migration is a complex phenomenon. Different types of migration (i.e., migrating with or without spouse) may have important ramifications for value change. Future research incorporating diverse types of migration will offer a more complete picture. In addition, the data provide limited information on fertility behavior that would allow a thorough examination of the fertility implications of female 
migration. Nevertheless, given the well-established link between fertility preferences and reproductive behaviors (Poston 2002), there are reasons to believe that the growing volume of female migration in China could have important implications for rebalancing China's malebiased sex ratios. Also, we have not taken into consideration the structural conditions facing migrant women in destinations. It is probable that the degree of marginalization facing migrant women in the destinations will be associated with the processes of sociocultural change in origin communities. In addition, the results are drawn from cross-sectional data, thereby limiting our ability to directly examine how migration may spur a shift in son preference. Improved data that are longitudinal and with information on migrants' conditions at destinations, and migrants' economic and non-economic transfers, will enable future research to draw more definitive conclusions, and to better understand the multiple economic and sociocultural consequences of migration for sending communities. Equally important, qualitative data will help more clearly illustrate the mechanisms underlying the relationship between migration and value change.

Whereas this study focuses on internal migration in China, the findings that the broader social and economic transformations fostered by gendered migration operate at multiple levels and intertwine with local context have implications beyond the study setting. Investigating the relationship between migration and cultural values in settings with distinct gendered migration patterns and cultural norms may prove a valuable approach for uncovering the complexity of this relationship. 


\section{Endnotes}

1. Son preference is much weaker in urban than in rural China (Attané 2009). This difference is explained by factors such as the greater ideational support for gender equality, an increase in women's earning opportunities, adoption of neo-local residences among married couples, and a better social welfare system in urban areas.

2. Despite the persistent son preference, research has pointed to recent ideological departures from patriarchal norms (Yan 2003). Within the broader pattern of distorted sex ratios, a small group of young rural couples with one daughter were indifferent about trying again for a son, and there is a gradual shift in obligation for parental care away from sons toward both sons and daughters.

3. This study emphasizes inter-county and inter-province migration, following previous research in China (Liang and Ma 2004). Intra-county migration often involves limited change in social environment, as many intra-county migrants move to rather similar socioeconomic settings and even to non-urban areas. Another reason for our focus is that information on the year of first outmigration (the cumulative migration measure) is available only for out-of-county migration. 


\section{References}

Attane', I. (2009). The determinants of discrimination against daughters in China: Evidence from a provincial-level analysis. Population Studies, 63(1), 87-102.

Banister, J (2004). Shortage of girls in China today. Journal of Population Research, 21(1), $19-45$.

Chafetz, J. S. (1999). Structure, agency, consciousness and social change in feminist theories: A conundrum. In Scott G. McNall \& Gary N. Howe (Eds.), Current perspectives in social theory (pp. 145-164). New York: JAI Press.

Cohen, M. (2005). Kinship, contract, community, and state: Anthropological perspectives on China. Stanford, CA: Stanford University Press.

Curran, S., \& Rivero-Fuentes, E. (2003). Engendering migrant networks: The case of Mexican migration. Demography, 40(2), 289-307

Curran, S., Shafer, S., Donato, K., \& Garip, F.(2006). Mapping gender and migration in sociological scholarship: Is it segregation or integration? International Migration Review, 40(1), 199-223.

Roodman, D. (2009) Estimating fully observed recursive mixed-process models with CMP. Center for global development working paper 168.

Donato, K., Gabaccia, D., Holdaway, J., Manalansan, M., \& Pessar, P. (2006). A glass half full? gender in migration Studies. International Migration Review, 40(1), 3-26.

Du, Y., Park, A., \& Wang, S. (2005). Migration and rural poverty in China. Journal of Comparative Economics, 33(4), 688-709.

Ebenstein, A., \& Leung, S. (2010). Son preference and access to social insurance: evidence from China's rural pension program. Population and Development Review, 36(1), 47-70.

Enarson, E. P., \& Morrow, B. (1998). The gendered terrain of disaster: Through women's eyes. Westport, CT: Praeger.

Fan, C. (2008). China on the move: Migration, the state, and the household. The China Quarterly, 196, 924-956.

Fan, C.C., \& Huang, Y. (1998). Waves of rural brides: Female marriage migration in China. Annals of the Association of American Geographers, 88(2), 227-251.

Foner, N. (2002). Immigrant women and work in New York City, then and now. In P. G. Min (Ed.), Mass migration to the United States: Classical and contemporary trends (pp. 231252). Walnut Creek, CA: Altamira Press.

Graham, M., Larsen, U., \& Xiping, X. (1998). Son preference in Anhui Province, China. International Family Planning Perspectives, 24(2), 72-77. 
Grasmuck, S., \& Pessar, P. (1991). Between two islands dominican international migration. Berkeley: University of California Press.

Gupta, M., Jiang, Z., Li, B., Zhenming, X., Chung, W., \& Hwa-Ok, B. (2003). Why is son preference so persistent in East and South Asia? The Journal of Development Studies, 40(2), $153-187$.

Halliday, T. (2006). Migration, risk, and liquidity constraints. Economic Development and Cultural Change, 54, 893-925.

Hesketh, T., Li, L., \& Xing, Z. W. (2005). The effect of China's one-child family policy after 25 years. New England Journal of Medicine, 353(11), 1171-1176.

Hondagneu-Sotelo, P. (1994). Gendered transitions: Mexican experiences of immigration. Berkeley, CA: University of California Press.

Inglehart, R. (1989). Culture shift in advanced industrial society. Princeton: Princeton University Press. Inglehart, R., \& Norris, P. (2003). Rising tide: Gender equality and cultural change around the world. Cambridge: Cambridge University Press.

IOM (International Organization for Migration). (2010). World migration report. Geneva: International Organisation for Migration.

Jacka, T. (2005). Rural women in urban China gender, migration, and social change. Armonk, NY: M.E. Sharpe.

Kanaiaupuni, S. (2000). Reframing the migration question: An analysis of men, women, and gender in Mexico. Social Forces, 78(4), 1311-1347.

Kibria, N. (1990). Power, patriarchy, and gender conflict in the Vietnamese immigrant community. Gender and Society, 4(1), 9-24.

Levitt, P. (1998). Social remittances: Migration driven local-level forms of cultural diffusion. International Migration Review, 32(4), 926-948.

Levitt, P., \& Lamba-Nieves, D. (2011). Social remittances revisited. Journal of Ethnic and Migration Studies, 37(1), 1-22.

Li, J., \& Lavely, W. (2003). Village context, women's status, and son preference among rural Chinese women. Rural Sociology, 68(1), 87-106.

Liang, Z., \& Ma, Z. (2004). China's floating population: New evidence from the 2000 census. Population and Development Review, 30(3), 467-488.

Lindstrom, D., \& Muñoz-Franco, E. (2005). Migration and the diffusion of modern contraceptive knowledge and use in rural Guatemala. Studies in Family Planning, 36(4), $277-288$.

Miller, B. D. (1981). The endangered sex: Neglect of female children in rural North India. Ithaca: Cornell University Press. 
Ming, J., \& Zhang, J. (2011). Return intentions, migration costs, and remittances. South China Population, 26, 48-56.

Mishra, A., \& Goodwin, B. (1997). Farm income variability and the supply of off-farm labor. American Journal of Agricultural Economics, 79(3), 880-887.

Montgomery, M., \& Casterline, J. (1996). Social learning, social influence, and new models of fertility. Population and Development Review, 22, 151-175.

Murphy, R. (2002). How migrant labor is changing rural China (Cambridge modern China series.). Cambridge, NY: Cambridge University Press.

Murphy, R., Tao, R., \& Xi, L. (2011). Son preference in rural China: patrilineal families and socioeconomic change. Population and Development Review, 37(4), 665-690.

National Bureau of Statistics. (2011a). China Statistics yearbook. Beijing: China Statistics Press.

NBS (National Bureau of Statistics). (2011b). Demographic Statistics from the 2010 Census. Beijing: China Statistics Press.

Parish, W., \& Whyte, M. (1978). Village and family in contemporary China. Chicago: University of Chicago Press.

Parrado, E., \& Flippen, C. (2005). Migration and gender among Mexican women. American Sociological Review, 70(4), 606-632.

Pedraza, S. (1991). Women and migration: The social consequences of gender. Annual Review of Sociology, 17, 303-325.

Peek, C. W., Lowe, G. D., \& Susan Williams, L. (1991). Gender and god's word: Another look at religious fundamentalism and sexism. Social Forces, 69(4), 1205-1221.

Pessar, P., \& Mahler, S. (2003). Transnational migration: Bringing gender in. International Migration Review, 37(3), 812-846.

Portes, A. (2010). Migration and social change: Some conceptual reflections. Journal of Ethnic and Migration Studies, 36(10), 1537-1563.

Poston, D. (2002). Son preference and fertility in China. Journal of Biosocial Science, 34(3), 333-347. Rabe-Hesketh, S., \& Skrondal, A. (2012). Multilevel and longitudinal modeling using stata (3rd ed.). College Station, TX: Stata Press.

Roberts, K., Connelly, R., \& Xie, Z. (2004). Patterns of temporary labor migration of rural women from Anhui and Sichuan. The China Journal, 52, 49-70.

Santos, G. (2006). The anthropology of Chinese kinship. A critical overview. European Journal of East Asian Studies, 5(2), 275-333.

Solinger, D. (1999). Contesting citizenship in urban China: Peasant migrants, the state, and the logic of the market. Berkeley: University of California Press. 
Song, S., \& Burgard, S. A. (2008). Does son preference influence children's growth in height? A comparative study of Chinese and filipino children. Population Studies, 62(3), 305-320.

Stacey, J. (1983). Patriarchy and socialist revolution in China. Berkeley: University of California Press.

Taylor, E. J. (1999). The new economics of labour migration and the role of remittances in the migration process. International Migration, 37(1), 63-88.

Wang, G. (2007). The risk management system of natural disaster in agriculture. Social Science Research, 4, 27-31.

Yan, Y. (2003). Private life under socialism: Love, intimacy, and family change in a Chinese village, 1949-1999. Stanford, CA: Stanford University Press.

Zeng, Y., Ping, T., Baochang, G., Yi, X., Li, B., \& Li, Y. (1993). Causes and implications of the recent increase in the reported sex ratio at birth in China. Population and Development Review, 19(2), 283-302.

Zhang, H. (2007). China's new rural daughters coming of age: Downsizing the family and firing up cash earning power in the new economy. Signs, 32(3), 671-698.

Zheng, Z., Zhou, Y., Zheng, L., Yang, Y., Zhao, D., Lou, C., \& Zhao, S. (2001). Sexual behaviour and contraceptive use among unmarried, young women migrant workers in five cities in China. Reproductive Health Matters, 9(17), 118-127. 
Table 1. Proportions of Household and Village Out-migration Measures (standard deviations in parentheses; $N=2,196)$

\begin{tabular}{lcc}
\hline & Current measure & Cumulative measure \\
\hline Household overall emigration ratio & 0.205 & 0.253 \\
& $(0.241)$ & $(0.264)$ \\
Village overall emigration ratio & 0.211 & 0.259 \\
& $(0.090)$ & $(0.096)$ \\
Household female emigration ratio & 0.113 & 0.153 \\
& $(0.237)$ & $(0.276)$ \\
Household male emigration ratio & 0.261 & 0.336 \\
& $(0.340)$ & $(0.377)$ \\
Village female emigration ratio & 0.136 & 0.170 \\
& $(0.089)$ & $(0.101)$ \\
Village male emigration ratio & 0.278 & 0.337 \\
& $(0.117)$ & $(0.119)$ \\
Household difference in female and male emigration ratio & -0.148 & -0.183 \\
& $(0.364)$ & $(0.395)$ \\
Village difference in female and male emigration ratio & -0.142 & -0.167 \\
& $(0.103)$ & $(0.107)$ \\
\hline
\end{tabular}


Table 2. Descriptive Statistics of Variables Included in the Analysis $(N=2,196)$

\begin{tabular}{|c|c|c|}
\hline & Mean or Proportion & Standard Deviation \\
\hline Son preference (ranging from 1 to 5 ; higher value indicates greater preference) & 3.82 & $(1.33)$ \\
\hline Respondent has migration experience (return migrant) & 0.18 & --- \\
\hline Age & 49.35 & $(11.31)$ \\
\hline Male & 0.60 & --- \\
\hline Currently married & 0.96 & --- \\
\hline Years of education & 6.23 & $(3.34)$ \\
\hline \multicolumn{3}{|l|}{ Religion } \\
\hline Not religious & 0.56 & --- \\
\hline Eastern religion & 0.41 & --- \\
\hline Western religion & 0.03 & --- \\
\hline Having at least one son & 0.71 & --- \\
\hline Arable landholdings per capita $(\mathrm{mu})$ & 1.55 & $(1.92)$ \\
\hline Household per capita annual income (yuan; logged) & 8.32 & $(1.04)$ \\
\hline Parents or parents-in-law in household & 0.42 & --- \\
\hline Household ancestor worship & 0.33 & --- \\
\hline Proportion of villagers with high school education or above & 0.13 & $(0.13)$ \\
\hline Village income per capita (yuan; logged) & 8.13 & $(0.64)$ \\
\hline Village collective ancestor worship & 0.34 & -- \\
\hline
\end{tabular}

Note: The "mu" is a traditional unit of land area in China. One mu is about 675 square meters. The "yuan" is the Chinese currency. In 2008, one US dollar was about 6.9 Chinese yuan. 
Table 3. Coefficients of Instrumental Variable Estimation with Ordered Probit Regressions Predicting Son Preference (robust standard errors adjusting for clustering)

\begin{tabular}{|c|c|c|}
\hline & Current measure & Cumulative measure \\
\hline Village difference in female and male emigration ratio & $\begin{array}{l}-5.420^{*} \\
(2.707)\end{array}$ & $\begin{array}{r}-4.230+ \\
(2.410)\end{array}$ \\
\hline Household difference in female and male emigration ratio & $\begin{array}{l}-0.167 \\
(0.129)\end{array}$ & $\begin{array}{l}-0.153 \\
(0.134)\end{array}$ \\
\hline Respondent is a return migrant & $\begin{array}{l}-0.071 \\
(0.100)\end{array}$ & $\begin{array}{l}-0.061 \\
(0.103)\end{array}$ \\
\hline Age & $\begin{array}{l}0.007^{*} \\
(0.003)\end{array}$ & $\begin{array}{l}0.008^{*} \\
(0.003)\end{array}$ \\
\hline Male & $\begin{array}{c}0.128 \\
(0.081)\end{array}$ & $\begin{array}{c}0.131 \\
(0.079)\end{array}$ \\
\hline Years of education & $\begin{array}{l}-0.023 * \\
(0.011)\end{array}$ & $\begin{array}{l}-0.026^{*} \\
(0.012)\end{array}$ \\
\hline Currently married & $\begin{array}{c}0.161 \\
(0.144)\end{array}$ & $\begin{array}{c}0.192 \\
(0.166)\end{array}$ \\
\hline Having at least one son & $\begin{array}{l}0.146^{*} \\
(0.070)\end{array}$ & $\begin{array}{l}0.132+ \\
(0.075)\end{array}$ \\
\hline Religion (ref. no religion) & & \\
\hline Eastern religion & $\begin{array}{l}0.068 \\
(0.080)\end{array}$ & $\begin{array}{c}0.055 \\
(0.083)\end{array}$ \\
\hline Western religion & $\begin{array}{c}0.127 \\
(0.143)\end{array}$ & $\begin{array}{c}0.116 \\
(0.151)\end{array}$ \\
\hline Household arable landholdings per capita & $\begin{array}{l}-0.022 \\
(0.018)\end{array}$ & $\begin{array}{l}-0.029 \\
(0.021)\end{array}$ \\
\hline Household per capita annual income (logged) & $\begin{array}{c}0.022 \\
(0.032)\end{array}$ & $\begin{array}{l}0.007 \\
(0.033)\end{array}$ \\
\hline Parents or parents-in-law in household & $\begin{array}{c}0.064 \\
(0.077)\end{array}$ & $\begin{array}{c}0.066 \\
(0.078)\end{array}$ \\
\hline Household ancestor worship & $\begin{array}{l}0.181^{*} \\
(0.087)\end{array}$ & $\begin{array}{l}0.173^{*} \\
(0.084)\end{array}$ \\
\hline Proportion of villagers with high school education or above & $\begin{array}{l}-0.329 \\
(0.353)\end{array}$ & $\begin{array}{l}-0.116 \\
(0.278)\end{array}$ \\
\hline Village income per capita (logged) & $-0.187^{*}$ & $-0.198^{*}$ \\
\hline
\end{tabular}


Village collective ancestor worship

Coefficient of natural shock in first-stage regression

(standard error)

F-test for weak instrument

Test for Endogeneity (p-value)
(0.075)

$0.127+$

(0.074)

$0.021 * * *$

(0.006)

15.6

$\mathrm{p}<0.001$

0.184

2196
$(0.082)$

$0.229^{*}$

(0.105)

$0.027 * * *$

$(0.007)$

17.6

$\mathrm{p}<0.001$

0.255

2196

$\dagger \mathrm{p}<0.1 ; * \mathrm{p}<0.05 ; * * \mathrm{p}<0.01 ; * * * \mathrm{p}<0.001$

Note: A higher value of the dependent variable indicates greater son preference. Cut-points are omitted. 
Table 4. Coefficients of Multilevel Ordered Logistic Regressions Predicting Son Preference (standard errors in parentheses)

\begin{tabular}{|c|c|c|c|c|}
\hline & $\begin{array}{c}\text { Model } 1 \\
\text { Current } \\
\text { measure }\end{array}$ & $\begin{array}{c}\text { Model } 2 \\
\text { Cumulative } \\
\text { measure }\end{array}$ & $\begin{array}{c}\text { Model } 3 \\
\text { Current } \\
\text { measure }\end{array}$ & $\begin{array}{c}\text { Model } 4 \\
\text { Cumulative } \\
\text { measure }\end{array}$ \\
\hline Household female emigration ratio & $\begin{array}{c}0.065 \\
(0.191)\end{array}$ & $\begin{array}{l}-0.054 \\
(0.168)\end{array}$ & & \\
\hline Household male emigration ratio & $\begin{array}{l}-0.022 \\
(0.141)\end{array}$ & $\begin{array}{c}0.109 \\
(0.143)\end{array}$ & & \\
\hline Village female emigration ratio & $\begin{array}{l}-1.739 * \\
(0.819)\end{array}$ & $\begin{array}{l}-1.276 \\
(0.632)\end{array}$ & & \\
\hline Village male emigration ratio & $\begin{array}{l}1.849 * \\
(0.842)\end{array}$ & $\begin{array}{l}1.488+ \\
(0.836)\end{array}$ & & \\
\hline $\begin{array}{l}\text { Household difference in female and male } \\
\text { emigration ratio }\end{array}$ & & & $\begin{array}{l}-0.086 \\
(0.113)\end{array}$ & $\begin{array}{c}0.033 \\
(0.119)\end{array}$ \\
\hline $\begin{array}{l}\text { Village difference in female and male } \\
\text { emigration ratio }\end{array}$ & & & $\begin{array}{r}-1.491 * \\
(0.752)\end{array}$ & $\begin{array}{l}-1.592^{*} \\
(0.810)\end{array}$ \\
\hline$N$ & 2196 & 2196 & 2196 & 2196 \\
\hline
\end{tabular}

$+\mathrm{p}<0.1 ; * \mathrm{p}<0.05 ; * * \mathrm{p}<0.01 ; * * * \mathrm{p}<0.001$

Note: A higher value of the dependent variable indicates greater son preference. Other covariates are similar as in Table 3 and are omitted. 
Figure 1. The Role of Village Gendered Emigration by Cultural Context

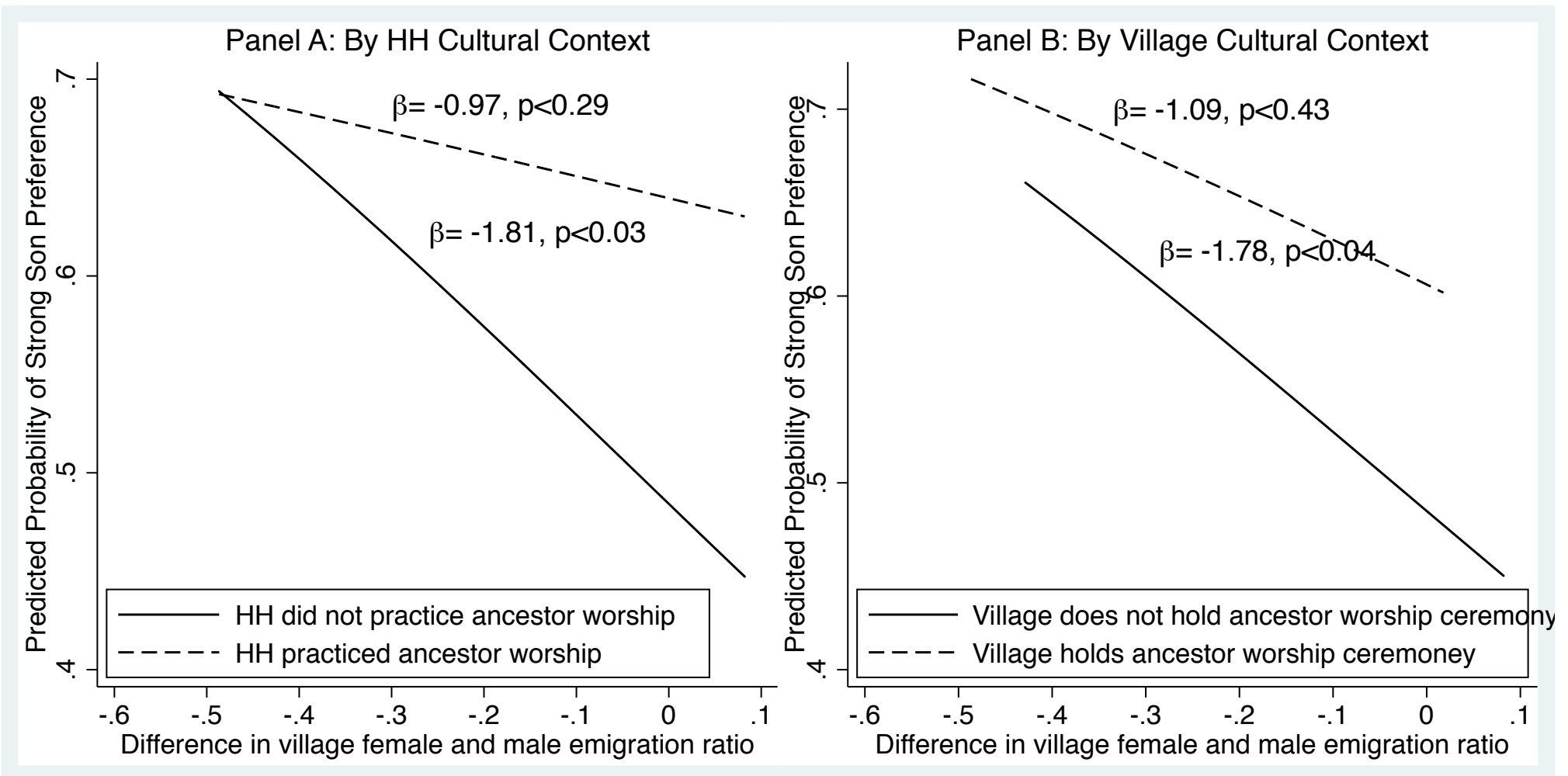

Note: The estimates are based on multilevel ordered logit models in Model 4 in Table 4. 


\section{Appendix A. Sampling Strategy}

This national survey was carried out by China Academy of Science, Center for Chinese Agricultural Policy (CAS-CCAP). In selecting the sample, the country was divided into six commonly recognized geographical regions (State Council Development Research Centre 2002). One province was randomly chosen from each region, resulting in six provinces: Shaanxi (Northwest), Sichuan (Southwest), Hebei (Central North), Jilin (Northeast), Jiangsu (East/Central Coast), and Fujian (Southeast). All counties in each province were then sorted into five strata (quintiles) according to their per capita gross value of industrial output. One county was randomly selected from each stratum, yielding a total of 30 counties. All townships in each county were sorted into two groups according to per capita net income - one with per capita net income above the median and the other below the median. One township was randomly selected from each group (60 townships). Following the same procedure for selecting townships, two villages were chosen from each township, yielding a total of 120 villages. For each village, a random sample of 20 households, based on the village household registration list, was sought to complete the interview. In each household, one adult was randomly selected for a face-to-face interview. Because of disruptions caused by the massive Sichuan earthquake in 2008, three villages were dropped from the sample, resulting in a total of 117 villages. About $5 \%$ of the sample was deleted due to missing information on any of the variables used in the analysis, yielding a final sample of 2,196. 


\section{Appendix B. Analyses of Remittance Behavior and Son Preference Using Supplementary Data on Migrants}

We first examine the remittance behavior of migrants using supplementary data on migrants in China. The migrant data are from the 2009 Twelve-city Migrant Survey. They were collected at about the same time and used standardized survey methods and questionnaires that were similar to the rural data. The survey was conducted in 12 cities across four major urbanized regions: the Yangtze River Delta (Jiangsu and Zhejiang Province), the Pearl River Delta (Guangdong province), Chengdu-Chongqing region (Sichuan Province and Chongqing Municipality), and Bohai Bay Area (Hebei and Shandong Province). In each of the four urbanized regions, one megalopolis (with an urban population of more than 2 million), one large city (500,000 - 2 million), and one smallmedium-sized city $(<500,000)$ were randomly selected. Due to the huge number of migrants in the megalopolis, only one urban district was sampled. In the large and small-medium-sized cities all urban districts in the city were targeted. Then 200 migrants were randomly selected in each city from the migrant registration list provided by the local Public Security Bureau or by the local government migrant administrative agency. The survey resulted in 2,398 migrants.

Results are displayed in Figure B1. Among unmarried migrants, women remit at a significantly higher rate to their parents than do men (67\% versus $60 \%)$, net of a range of demographic and socioeconomic characteristics. Among married migrants, the rate increases for men and decreases for women, but the gender difference is small and insignificant. These findings show the enduring commitment of many migrant daughters to their natal families. Although many migrant women face precarious work and living 
conditions in destinations and family life-cycle changes such as marriage may slightly alter migrant women's remittance patterns, they continue to remit their hard earned income to origin families.

We also compare the degree of son preference between migrants and rural residents, and between female and male migrants. As shown in Figure B2, values surrounding son preference are weaker for urbanward migrants than for rural residents. Specifically, when asked to what degree the respondent feels that it is necessary to have at least one son, over $60 \%$ of rural residents agreed or strongly agreed with the statement, compared to less than $45 \%$ of rural-to-urban migrants. In addition, female migrants tend to hold more egalitarian attitudes toward having a son than male migrants. We also examine changes in attitudes by duration of migration and find that the longer migrants stay in destination, the more gender egalitarian views they hold $(\beta=-0.011$, s.e. $=0.004$, $p=0.003)$. 


\section{Figure B1. Predicted Probability of Sending Remittances to Own Parents in the Past Year among Chinese Migrants}

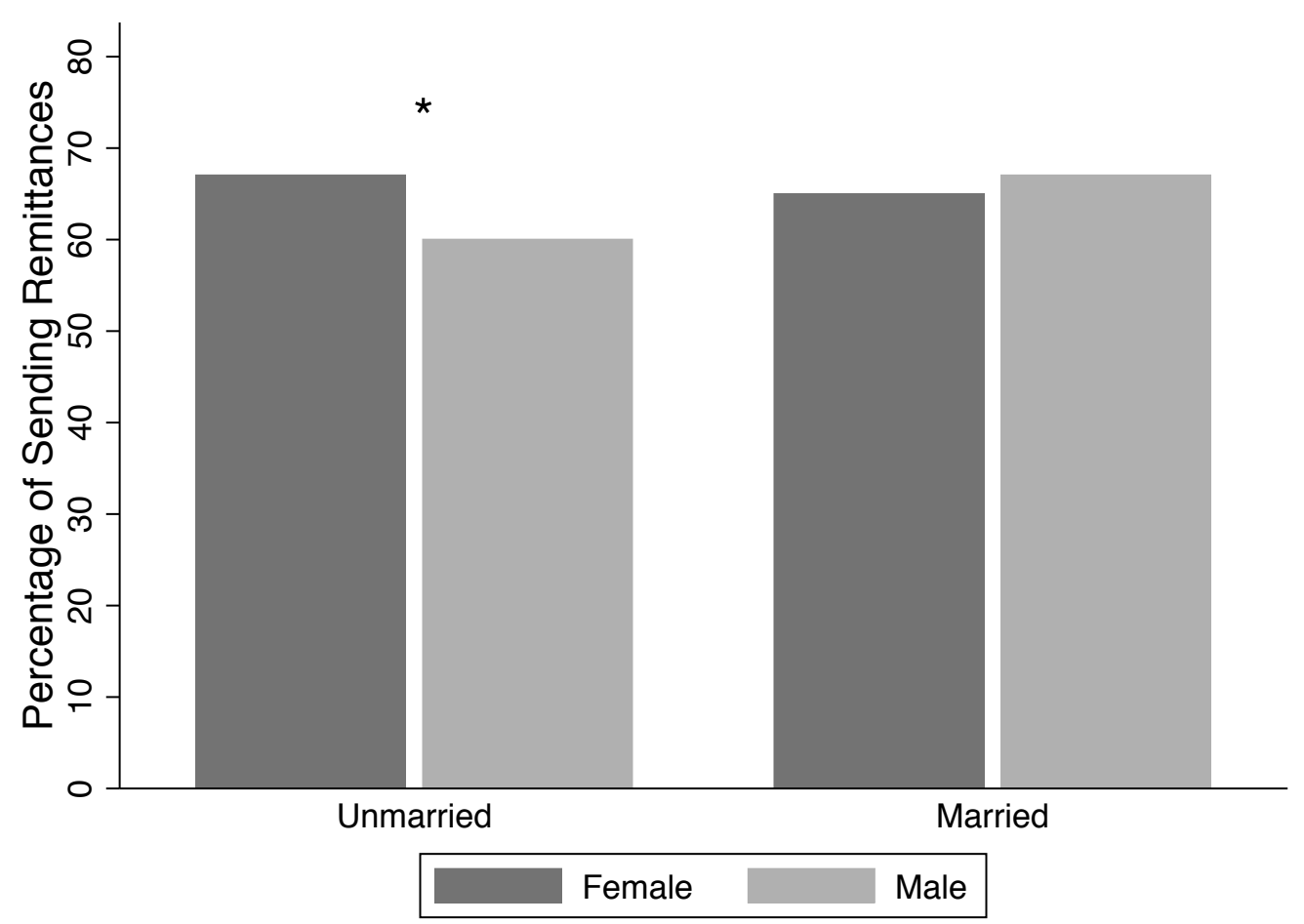

Note: Based on logistic regressions controlling for age, education, years since migration, whether the respondent has children left behind, number of provinces the migrant has been to, whether currently within-province migration, whether self employed, per capita family income at destination, current place of residence. This analysis was restricted to rural-origin migrants. The gender difference for unmarried migrants is significant at 0.05 level (indicated by *). The gender difference for married migrants is insignificant. 
Figure B2. Attitudes toward Son Preference by Migration Status, and among Migrants by Gender
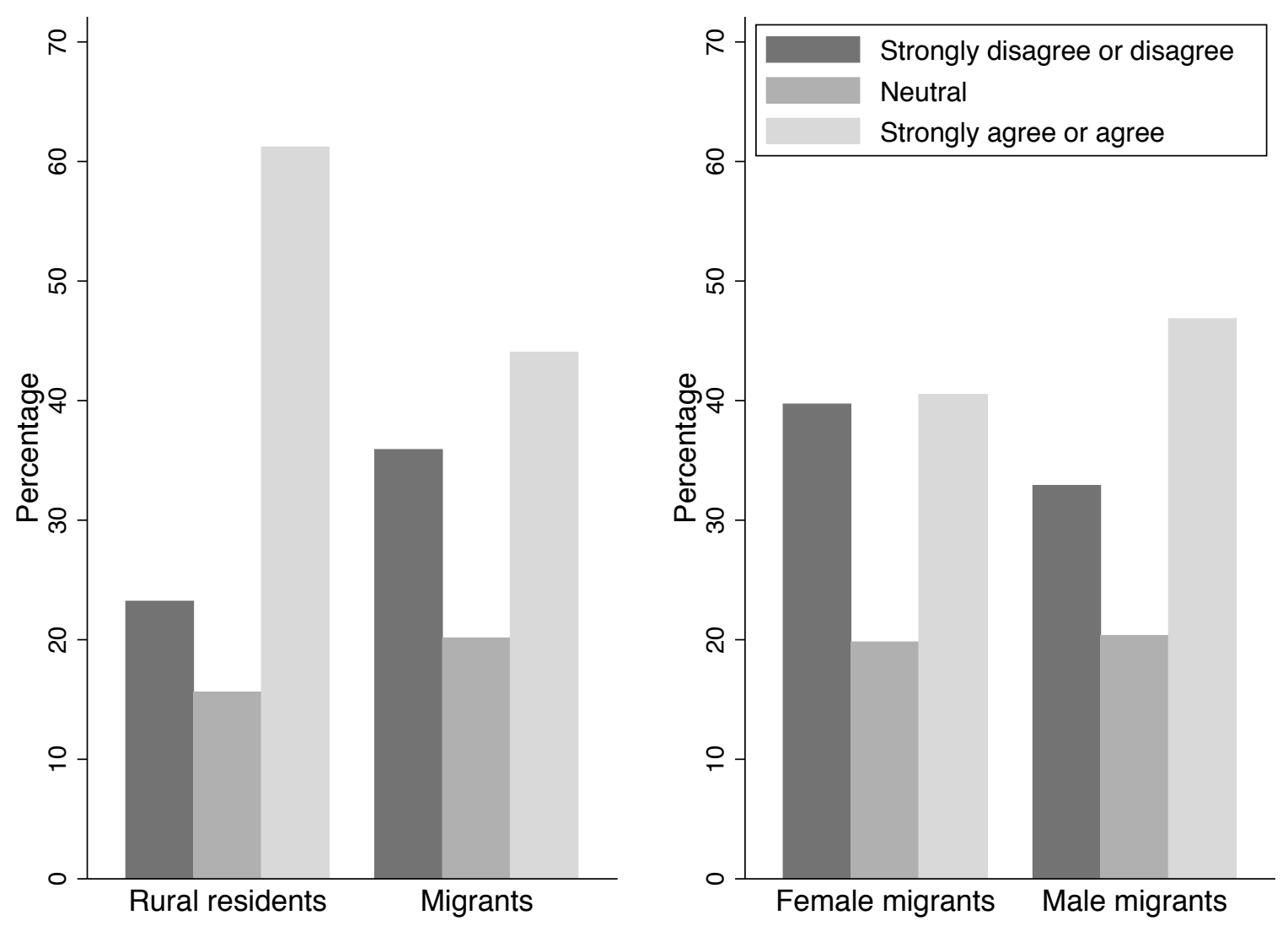

Note: Son preference is measured by agreement or disagreement with the statement: "I think that it is necessary to have at least one son." Chi-square test is significant at the 0.001 level for rural-migrant comparison, and significant at the 0.002 level for female-male comparison. 